\title{
Combining representations in working memory: A brief report
}

Article

Accepted Version

Towse, J. N. and Houston-Price, C. M. T. (2001) Combining representations in working memory: A brief report. British Journal of Developmental Psychology, 19 (3). pp. 319-324. ISSN 0261-510X doi:

https://doi.org/10.1348/026151001166100 Available at https://centaur.reading.ac.uk/5705/

It is advisable to refer to the publisher's version if you intend to cite from the work. See Guidance on citing.

To link to this article DOI: http://dx.doi.org/10.1348/026151001166100

Publisher: British Psychological Society

All outputs in CentAUR are protected by Intellectual Property Rights law, including copyright law. Copyright and IPR is retained by the creators or other copyright holders. Terms and conditions for use of this material are defined in the End User Agreement.

\section{www.reading.ac.uk/centaur}

\section{CentAUR}

Central Archive at the University of Reading 
Reading's research outputs online 


\section{Combining representations in working memory:}

\section{A brief report}

Towse, John N

(Department of Psychology, Royal Holloway, University of London)

Houston-Price, Carmel MT

(Department of Experimental Psychology, University of Oxford)

Acknowledgements. Carmel Houston-Price has been supported by an MRC studentship during preparation of this article, and described the data as part of an Experimental Psychology Society undergraduate project prize report, delivered to the EPS, March 1999. We are grateful for comments from anonymous reviewers and Anik de Ribaupierre. The data can obtained as an SPSS portable format file via the URL: http://www.pc.rhbnc.ac.uk/jt/combinationspan.zip.

Preprint version of: Towse, J.N., \& Houston-Price, C.M.T. (2001). Combining representations in working memory: A brief report. British Journal of Developmental Psychology ,19 , 319-324. For a final, authoritative version of the paper, please contact the first author. 


\begin{abstract}
A task combining both digit and Corsi memory tests was administered to a group of 75 children. The task is shown to share variance with standardised reading and maths attainments, even after partialling out performance on component tasks separately assessed. The emergent task property may reflect co-ordination skills, although several different refinements can be made to this general conclusion.
\end{abstract}

Combining representations in working memory: A brief report

There is undoubted appeal in the attempt to find simple psychological measurements that, by virtue of their 'purity', afford good indices of cognition. Simplicity has theoretical and practical advantages. Nonetheless, there are good reasons for considering more complex tasks also. After all, part of cognitive development involves the acquisition of intricate, complex and yet fundamental skills such as reading and mathematics. Simple tasks may be too impoverished to capture relevant psychological mechanisms in such real-world situations. We describe a dataset concerning the potential for integrated tasks to measure important individual differences among children, and consider some interpretative issues.

Yee, Hunt \& Pellegrino (1991) investigated co-ordination by combining tasks 'A' (e.g., a dynamic spatial display) and 'B' (e.g., a written statement) into an integrated task 'AB', assessing individual-differences and performance stability in A, B, and AB. To the 
extent that skills on $\mathrm{A}$ and $\mathrm{B}$ failed to explain $\mathrm{AB}$ variance, co-ordinating processes in the latter were implicated. However, there are methodological concerns in that one task element was not assessed completely independently (thus assessment of B - a written statement - referred to a spatial display, and was therefore an AB task with a very easy version of A).

The present study takes a similar conceptual approach to Yee et al. (1991, see also Emerson, Miyake \& Rettinger, 1999), considering individual differences in combining mental operations. However, here the focus is on explaining children's cognitive ability, as measured by attainment in reading and mathematics, with respect to memory skills. The empirical goal was to establish whether an assessment combining two commonly used memory tests - digit span and Corsi span - predicted children's scholastic skills, having controlled for the influence of both component operations. To our knowledge, such a study has not been previously reported. If reading and mathematics go beyond simple item retention, involving also co-ordination processes (King \& Just, 1991), then a memory task in which separate codes need to be combined ought to be predictive of these scholastic skills. Likewise, models of working memory in which different slave systems are controlled by a central executive (e.g., Baddeley, 1996) suggest individual differences in task combination ought to be separable from the elemental skills.

Method 
Three age groups were tested having obtained parental consent for each child: 29 '5-yearolds' (mean age 5;7, range 5;2 to 6;2), 24 '7-year-olds' (mean age 7;7, range 7;2 to $8 ; 1$ ) and 22 '9-year-olds' (mean age 9;5, range 9;1 to 10;1). The two older age groups completed the British Abilities Scales (BAS) number test in class supervised by their teacher. Individual testing took place in a quiet school room using the following fixed order: articulation speed, BAS word reading test, the span tests (in randomised order) and, for younger children, the relevant sections of the BAS number skills test. Articulation speed involved ten speeded repetitions of two digit pairs.

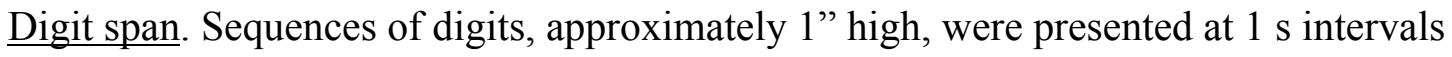
centre-screen on a 12 " monitor driven by a PC-compatible computer. Digit sequences (excluding two-syllable numbers 0 and 7) were prepared prior to the experiment by random selection without replacement. The experimenter transcribed children's verbal recall. List length began with two items and increased sequentially until recall errors were made on at least one of the two trials.

Corsi span. On a grey computer screen background, black outlines of eight (1.5" length) squares were continuously visible in fixed locations, forming no discernible spatial pattern (comparable with a Corsi block). On each trial, a sequence of squares — prepared as for digit stimuli — briefly changed colour to blue at $1 \mathrm{~s}$ intervals. Lists began with two items and followed digit span assessment, with children making pointing gestures in recalling spatial locations. 
Combination span. Essentially, this combined digit and Corsi tests, digits appearing inside the temporarily coloured squares. Following sequence presentation, children pointed to the square appearing first and verbally reported the digit that appeared there, before pointing to the next item etc. Lists began at length two (i.e. two locations and two digits) and proceeded as above.

Four sequence lists were required, two for digits and two for spatial locations. One list was used for the component span task and the other for combination span, with counterbalanced assignment. Span scores reflected the list length at which errors appeared, with partial credit at the next list length for correct responses (see Towse, Hitch \& Hutton, 1998).

Results and Discussion

A composite measure of school ability was calculated by averaging z-score transformations of BAS scores, while gender and incidental test order variables were ignored. Multivariate normality was explored by calculating Mahalanobis distances, with no overly problematic cases identified. The age-partialled correlation between BAS reading and number tests, $\underline{\mathrm{r}}(72)=.61, \underline{\mathrm{p}}<.01$, is similar to published norms (Elliot, 1983), suggesting a representative sample.

While individual differences provide the current focus, it is noteworthy that even though combination spans were lower than digit and Corsi spans (means=3.28, 3.92 and 
3.76 respectively, multivariate $\underline{\mathrm{F}}(2,71)=21.5, \underline{\mathrm{p}}<.01$, Wilks' Lambda $=.623)$, they were not just half their component values, even though a combination span score of two involves remembering two digits and two positions. One interpretation of this result is that children did employ multiple codes in remembering combination span sequences.

Table 1 about here

Table 1, describing the intercorrelations, confirms a relationship between combination span and scholastic ability. Yet this correlation might arise via the components of the combination span test. The key question, then, is whether combination span is a significant predictor of reading and maths ability after accounting for variance in digit and Corsi span skills (and other potential mediators, articulation speed and age). As shown in Figure 1, the partial correlation between combination span and ability remained significant.

Figure 1 about here

Figure 1 shows a composite measure of ability. The relationship was also calculated between combination span and each BAS test, partialling out all other variables including the other BAS score. If combination span, reading and number skill are linked by a uni-dimensional co-ordination factor, then controlling for one attainment test, by removing the shared variance, ought to render non-significant the correlation between combination span and the other. The partial correlation between combination 
span and reading was indeed non-significant, $\underline{\mathrm{r}}(67)=.172$, but that between combination span and number skill remained significant, $\underline{\mathrm{r}}(67)=.261, \underline{\mathrm{p}}<.01$. This latter finding, then, does not support a simple uni-dimensional account of the relationship between combination span, reading and number.

The present study provides empirical evidence that integrated tasks can yield unique information about scholastic attainment, over and above that gained from simpler component tasks. At a descriptive level, then, the data illustrate the methodological potential of the combination span test. At a theoretical level, one might be tempted to conclude that the partial correlation between combination span and ability reflects central executive co-ordination capacity, having controlled statistically for slave system performance (in a neuropsychological study, Fournet et al., 2000, suggest a combined span task requires executive control). The conclusion may be premature, however.

The domain-specific relationship between combination span and number skill is at odds with the idea of completely general combination span processes. More fundamentally, however, the reluctance to refer to combination span as a central executive task reflects the rather meagre explanatory value of this label. The present study establishes that combination span exhibits important emergent properties, but without further research, these could be explained in different ways, not all of which are executive in any direct sense. Potential explanatory accounts include children's strategic skills in devoting appropriate effort to each memory task (because both dimensions must be recalled correctly) and the impact of cross-dimensional associations which facilitate 
recall. Strategies that influence the timing of verbal recall (Cowan, 1999) may effect spatial representations (or vice versa), and differences in the susceptibility to interference across stimulus dimensions (Hale, Bronik \& Fry, 1997) might also be important. Potentially, these latter accounts represent architectural rather than executive control constraints. They are particularly attractive given the independent support available for them, but in any case the evidence makes it likely that a number of factors contribute to the present findings.

Some explanations, however, can be discounted. It was suggested by reviewers that assessing span with two trials per length might be unreliable (although used elsewhere; e.g. Kail \& Hall, 1999). However, low reliability would militate against finding significant correlations for any memory tests. Furthermore, digit and combination span correlate uniquely with ability, while Corsi span correlates uniquely with combination span but not with ability. So there is no simple explanation of "each task adds more" in predicting ability. In addition, although combination span is demanding, children remembered more total information than in component span conditions, so combination span cannot simply be a proxy for difficulty in general and, other things being equal, hard tasks should produce absolute changes in performance, not changes in individual-differences.

These theoretical questions apart, several findings encourage further research. For example, controlling for age removed the significant relationship between articulation speed and digit span, partial $\mathrm{r}(71)=.15$, yet controlling for articulation speed did not 
remove the relationship between digit span and age, partial $\underline{\mathrm{r}}(71)=.46, \underline{\mathrm{p}}<.01$ (c.f., Kail, 1997). Thus, changes in digit span with age are not merely a function of articulation speed. Also, digit span was a surprisingly strong correlate of ability (but see Hutton \& Towse, submitted). Finally, while a visually presented digit span task allows a spatial task to be superimposed, a replication of the combination span effect using auditory presentation would clearly enhance understanding of the task.

In summary, it is apparent that the data endorse the investment in the combination span task, encourage further exploration of integrated task performance, but require caution in making theoretical interpretations.

\section{References}

Baddeley, A. (1996). Exploring the central executive. Quarterly Journal of Experimental Psychology, 49A(1), 5-28.

Cowan, N. (1999). An embedded process model of working memory. In A. Miyake \& P. Shah (Eds.), Models of working memory (pp. 62-101). New York: Cambridge University Press.

Elliot, C. D. (1983). British Abilities Scale. Technical manual. Windsor, Berkshire: NFER-Nelson.

Emerson, M. J., Miyake, A., \& Rettinger, D. A. (1999). Individual differences in integrating and coordinating multiple sources of information. Journal of Experimental Psychology: Learning, Memory and Cognition. 25, 1300-1321. 
Fournet, N., Moreaud, O., Roulin, J. L., Naegele, B., \& Pellat, J. (2000). Working memory functioning in medicated Parkinson's disease patients and the effects of withdrawal of dopaminergic medication. Neuropsychology, 14(2), 247-253.

Hale, S., Bronik, M. D., \& Fry, A. F. (1997). Verbal and spatial working memory in school-age children: Developmental differences in susceptibility to interference. Developmental Psychology, 33(2), 364-371.

Hutton, U., \& Towse, J. N. (submitted). Short-term memory and working memory as indices of children's cognitive skills. Manuscript submitted for publication.

Kail, R. (1997). Phonological skill and articulation time independently contribute to the development of memory span. Journal of Experimental Child Psychology, 67, 57-68.

Kail, R., \& Hall, L. K. (1999). Sources of developmental change in children's wordproblem performance. Journal of Educational Psychology, 91(4), 660-668.

King, J., \& Just, M. A. (1991). Individual differences in syntactic processing: The role of working memory. Journal of Memory and Language, 30, 580-602.

Towse, J. N., Hitch, G. J., \& Hutton, U. (1998). A reevaluation of working memory capacity in children. Journal of Memory and Language, 39(2), 195-217.

Yee, P. L., Hunt, E., \& Pellegrino, J. W. (1991). Coordinating cognitive information: Task effects and individual differences in integrating information from several sources. Cognitive Psychology, 23, 615-680. 
Table 1. Raw (a) and age-partialled (b) correlations between variables.

a)

\begin{tabular}{lccccc}
\hline Variable & Age & $\begin{array}{c}\text { Articulation } \\
\text { rate }\end{array}$ & $\begin{array}{c}\text { Combination } \\
\text { span }\end{array}$ & Digit span & Corsi span \\
\hline Age & & & & & \\
Articulation rate & $\mathbf{- . 6 9 2}$ & & & & \\
Combination span & $\mathbf{. 5 9 0}$ & $\mathbf{- . 4 2 7}$ & & & \\
Digit span & $\mathbf{. 6 3 9}$ & $\mathbf{- . 5 3 6}$ & $\mathbf{. 5 9 5}$ & $\mathbf{. 3 6 7}$ & $\mathbf{. 5 3 6}$ \\
Corsi span & $\mathbf{. 4 9 7}$ & $\mathbf{- . 4 3 6}$ & $\mathbf{. 5 2 2}$ & $\mathbf{. 7 7 1}$ & $\mathbf{. 5 3 6}$ \\
BAS Ability & $\mathbf{. 8 1 2}$ & $\mathbf{- . 5 8 6}$ & $\mathbf{. 7 2 6}$ & $\mathbf{. 7 7 1}$ \\
\hline
\end{tabular}

(b)

\begin{tabular}{lcccc}
\hline Variable & $\begin{array}{c}\text { Articulation } \\
\text { rate }\end{array}$ & $\begin{array}{c}\text { Combination } \\
\text { span }\end{array}$ & Digit span & Corsi span \\
\hline Articulation rate & & & & \\
Combination span & -.045 & & & \\
Digit span & -.154 & $\mathbf{. 3 7 7}$ & & \\
Corsi span & -.155 & $\mathbf{. 3 2 6}$ & .081 & \\
BAS Ability & -.061 & $\mathbf{. 5 3 2}$ & $\mathbf{. 5 6 2}$ & $\mathbf{. 2 6 4}$ \\
\hline
\end{tabular}

Correlations significant at $\mathrm{p}<.05$ or stronger are displayed in bold. 
Figure 1. Diagram summarising the relationships between variables. Arrows indicate which pairs of variables are significantly correlated after controlling for all remaining measured variables. The numerical values represent partial correlation statistics. Other variable pairs, therefore, do not exhibit unique significant correlations. 


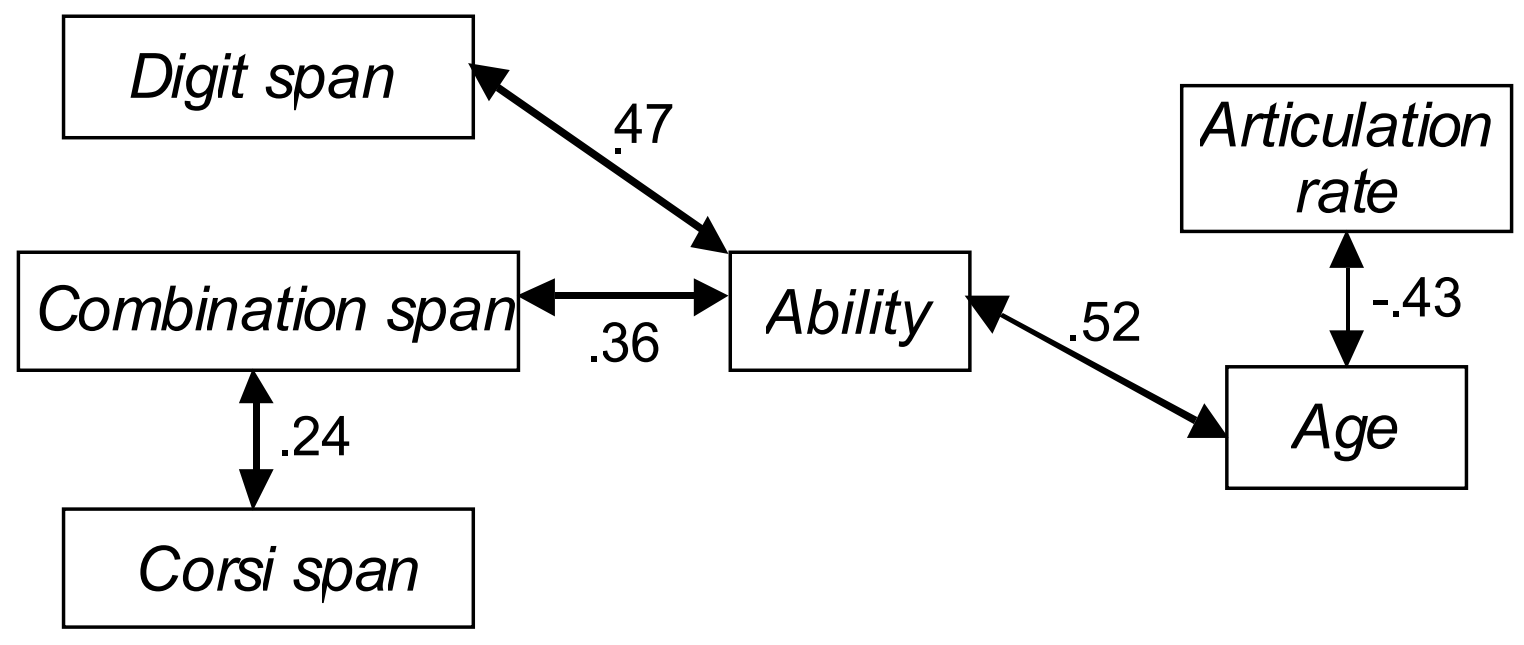

